\title{
Correction to: Global value chains: A review of the multi-disciplinary literature
}

\author{
Liena Kano ${ }^{1}$, Eric W. K. Tsang ${ }_{3}^{2}$ \\ and Henry Wai-chung Yeung ${ }^{3}$

\footnotetext{
${ }^{1}$ Haskayne School of Business, University of at Dallas, 800 W Campbell Rd., SM43, Richardson, TX 75080-3021, USA; ${ }^{3}$ Department of Geography and GPN@NUS Centre, National University of Singapore, 1 Arts Link,

Singapore 117570, Singapore
} \\ Calgary, Calgary, AB T2N 1N4, Canada; ${ }^{2}$ Naveen \\ Jindal School of Management, University of Texas
}

\section{Correspondence:}

L Kano, Haskayne School of Business, University of Calgary, Calgary, AB T2N 1N4, Canada

e-mail: liena.kano@haskayne.ucalgary.ca
Journal of International Business Studies (2020) 51, 1353.

https://doi.org/ 10.1057/s4 I 267-020-00322-0

\section{CORRECTION TO: \\ JOURNAL OF INTERNATIONAL BUSINESS STUDIES (2020) \\ https://doi.org/10.1057/s41267-020-00304-2}

This paper has been corrected owing to a production error. Table 3 has been corrected as follows: Buckley $(2009 a, b)$ was changed to Buckley (2009b), and the asterisk after Liu \& Dicken (2006) was removed. Additionally, in the reference section, the asterisk for the reference Liu, W., \& Dicken, P. (2006) was added. No other changes to the article have been made. We apologise for any inconvenience caused to our readers.

Publisher's Note Springer Nature remains neutral with regard to jurisdictional claims in published maps and institutional affiliations.
The original article can be found online at https://doi.org/10.1057/s41267-020-00304-2. Online publication date: 30 March 2020 